\title{
Incorporating Aluminum Into the Structure of SBA-15 by Adjusting the pH and Adding $\mathrm{NaF}$
}

\author{
Manuela Silva Martins de Oliveira ${ }^{a}$, Lindiane Biesekia, , Ana Ellen Valentim de Alencara, \\ Tiago Pinheiro Braga ${ }^{a} \oplus$, Sibele Berenice Castellã Pergher ${ }^{a} *$ (우
}

\author{
${ }^{a}$ Laboratório de Peneiras Moleculares (LABPEMOL), Instituto de Química, Universidade Federal do \\ Rio Grande do Norte (UFRN), 59078-900, Campus Universitário Lagoa Nova, Natal, RN, Brasil \\ ${ }^{b}$ Programa de Pós-Graduação em Ciência e Engenharia de Materiais (PPGCEM), Universidade \\ Federal do Rio Grande do Norte (UFRN), 59078-900, Campus Universitário Lagoa Nova, Natal, RN, \\ Brasil
}

Received: October 04, 2018; Revised: January 22, 2019; Accepted: March 25, 2019

The $\mathrm{Al}$ incorporation on SBA-15 type material and the effects of $\mathrm{pH}$ adjusting and presence of $\mathrm{NaF}$ were studied. The direct synthesis method was performed for comparison. The following parameters were evaluated: the $\mathrm{Si} / \mathrm{Al}$ ratio, $\mathrm{pH}$ increase, and amount of $\mathrm{NaF}$ added. These parameters have a great influence on the synthesis of the mesoporous $\mathrm{Al} / \mathrm{SBA}-15$ type, but the $\mathrm{pH}$ the most influential parameter for the incorporation of Al into the SBA-15 structure. The formation of the SBA-15 structure was observed through the direct synthesis method. However, aluminum is not present in the material. The increase in $\mathrm{pH}$ contributed to the formation of a disorganized material. By EDX, it was observed that synthesis with a $\mathrm{Si} / \mathrm{Al}=5$ ratio and $\mathrm{pH}$ approximately 4 provides materials containing aluminum. When the amount of aluminum during the synthesis is lower, a pH of approximately 8 is required to incorporate aluminum into the final material. The Al-NMR analysis showed that it was possible to insert aluminum in the structure of SBA-15, but with the presence of aluminum hexa and pentacoordinated. In the catalytic test of the dehydration reaction of ethanol, the samples with higher aluminum contents showed better catalytic performance due to its higher acidity.

Keywords: $A l / S B A-15$, direct synthesis, $p H$ adjustment.

\section{Introduction}

Zeolites are probably the most industrially used catalysts and may be applied in petroleum refining, petrochemical and organic synthesis to produce petrochemical and specific products, particularly when working with molecules with diameters smaller than $1 \mathrm{~nm}$. These materials have several characteristics that allow their application in catalysis, such as high specific area and thermal stability, adsorption capacity, possibility of generating acid sites in their structure, channel and cavity sizes that are relevant to many molecules of interest, and structural complexity. These characteristics allow different types of selectivity, that is, the targeting of the catalytic reaction to a desired product, avoiding undesirable side reactions ${ }^{1}$.

However, zeolites become inadequate when working with bulky organic molecules because their pore size restricts and limits their application to small molecules. This deficiency reinforced the search and need for materials with more accessible pore diameters when considering reactions of bulky molecules, such as heavy petroleum fractions.

The first class of mesoporous materials reported is known as the M41S family, and they were synthesized for the first time in 1992 by Mobil Oil Corporation ${ }^{2}$. One of the

*e-mail: sibelepergher@gmail.com members that stands out most in this family is the MCM-41. Compared to zeolite materials, materials such as MCM-41 exhibit a narrow pore size distribution. However, their pore systems can be controlled, so dimensions between 1.5 and $10 \mathrm{~nm}$ can be obtained ${ }^{3}$.

The main property of the M41S family which has attracted researchers is their high hydrocarbon adsorption capacity due to their larger pore size and high thermal stability. However, despite this high thermal stability, the mechanical compression of this material in the presence of adsorbed water eventually changes its structure, and the low hydrothermal stability has limited its application especially in catalytic reactions.

In 1998, a new family of mesoporous silicas with highly ordered mesopores was synthesized in acid medium using nonionic triblock copolymers. Different materials with a variety of periodic arrangements have been elaborated and denominated SBA, "Santa Barbara Amorphous". Among these, SBA-15 has aroused great interest due to its interesting characteristics ${ }^{4}$.

SBA-15 is a microporous and mesoporous material with a two-dimensional hexagonal structure similar to MCM-41, and it has large and adjustable pores of up to $30 \mathrm{~nm}^{5}$. The most interesting properties of SBA-15 are its larger pore diameters, thicker pore walls and the presence of micropores 
interconnecting the mesopores, which consequently result in greater hydrothermal stability compared to MCM-41. The walls of mesoporous materials have amorphous characteristics. Additionally, these materials have low acidity since it is a purely siliceous solid. On the other hand a heteroatom such as aluminum, can be inserted into the neutral silica network to generate acidic surfaces.

However, the incorporation of aluminum into mesoporous silicas is not simple. The main problem in obtaining aluminumcontaining SBA-15 is that the synthesis occurs at a low $\mathrm{pH}$ of approximately 1 , where the aluminum is only present in its cationic form $\left(\mathrm{Al}^{3+}\right)$ and thus cannot be inserted into the structure of the SBA-15. In general, the easy dissociation of the Al-O-Si bonds under acid hydrothermal conditions and the difference between the rates of hydrolysis of silicon and aluminum make the insertion of aluminum even more difficult ${ }^{6-8}$.

Several approaches have been adopted to overcome some of the problems caused by the difference in hydrolysis reactivity and the condensation of silicon and aluminum. Direct synthesis methods, where the aluminum source is added directly to the synthesis gel, can provide materials with higher specific area and higher pore volumes. However, this method presents a high amount of the extra aluminum network due to the low $\mathrm{pH}$ of synthesis ${ }^{9}$. Post-synthesis methods may exhibit larger amounts of Lewis and Brönsted acid sites. However, the heteroatoms can be partially leached during the filtration, since aluminum is incorporated by immersing the solid SBA-15 in an aqueous solution, followed by filtration and calcination.

Another method, known as $\mathrm{pH}$-adjusting method, has been observed to be quite effective in regard to the insertion of heteroatoms, such as aluminum, into mesoporous silica materials in a strongly acid medium with high aluminum content in the network. In this method, the aluminum source is added to the initial reaction mixture in a strongly acidic medium $(\mathrm{pH}<1)$, as in the case of direct synthesis. When the mesostructure is formed, the $\mathrm{pH}$ of the system is adjusted to a neutral $\mathrm{pH}$ of approximately 7.5 , followed by a hydrothermal treatment in which a large amount of aluminum can be introduced into the SBA-15 network ${ }^{6}$. In conjunction with the $\mathrm{pH}$ adjusting process, the addition of $\mathrm{NaF}$ may promote the formation of an $\mathrm{Al} / \mathrm{SBA}-15$ type material that is more resistant to hydrothermal treatment ${ }^{10}$. $\mathrm{NH}_{4} \mathrm{~F}$ is used to accelerate the TEOS (Tetra Ethyl Orthosilicate) hydrolysis process to approach the hydrolysis rate of aluminum isopropoxide, producing materials with $\mathrm{Al}$ incorporated in the tetrahedral form ${ }^{11}$.

Different approaches to the synthesis of mesoporous materials with similar structures and containing Si and Al are known. These synthesis methods and the parameters that influence the final material enable us to control the size of the pores, the morphology and the properties of the obtained material. Although there are some papers using the of the $\mathrm{pH}$-adjusting approaches, the optimization of the different parameters and new methodologies for aluminum incorporation remains an open research topic. Thus, the aim of this work was to synthesize mesoporous molecular sieves of the Al/SBA-15 type through the route of synthesis using $\mathrm{pH}$ adjusting. Parameters such as the $\mathrm{Si} / \mathrm{Al}$ ratio, $\mathrm{NaF}$ addition and synthesis $\mathrm{pH}$ were varied in order to evaluate the joint effect of these variables on Al insertion and also in the preservation of the structural organization of the materials, that can be applied in catalysis. Some of the prepared materials were also tested in an ethanol dehydration reaction, noting their ability to convert and selectivity for ethylene and/or diethylether.

\section{Materials and Methods}

\subsection{Materials}

For the synthesis of the Al/SBA-15 materials, Pluronic P123 (Sigma Aldrich), Tetraethylorthosilicate (Sigma Aldrich 98\%), Sodium Fluoride (99\% Dynamic) and Ammonium Hydroxide (Alphatec 28 - 30\%) were used. Aluminum Hexahydrate $\left(\mathrm{AlCl}_{3} \cdot 6 \mathrm{H}_{2} \mathrm{O}\right)$ (Sigma Aldrich) and Aluminum Hydroxide $\mathrm{Al}(\mathrm{OH})_{3}$ (Merck) were used as sources of aluminum.

\subsection{Direct Synthesis of Al/SBA-15}

The Al/SBA-15 was prepared according to the methodology adapted from the literature ${ }^{4}$. The molar composition of the synthesis gel was set as $0.057 \mathrm{SiO}_{2}: 0.006 \mathrm{Al}_{2} \mathrm{O}_{3}: 0.001$ P123: $0.338 \mathrm{HCl}: 9.005 \mathrm{H}_{2} \mathrm{O}$ and a $\mathrm{Si} / \mathrm{Al}$ ratio of 5 . In this procedure, $\mathrm{P} 123$ and an aqueous solution of $\mathrm{HCl}$ were kept under stirring at $35^{\circ} \mathrm{C}$ until complete dissolution of the polymer. Then, TEOS and $\mathrm{AlCl}_{3} \cdot 6 \mathrm{H}_{2} \mathrm{O}$ were added simultaneously. The mixture was stirred for $7.5 \mathrm{~h}$ at $45^{\circ} \mathrm{C}$ and then placed in Teflon autoclaves which were taken to a static oven at $90{ }^{\circ} \mathrm{C}$ for $15.5 \mathrm{~h}$. The obtained material was filtered and washed with distilled water. The final product was dried and calcined in a muffle furnace at $600{ }^{\circ} \mathrm{C}$ for $5 \mathrm{~h}$ employing a heating rate of $2^{\circ} \mathrm{C} / \mathrm{min}$. The obtained sample was named Al/SBA-15.

\subsection{Direct Synthesis of Al/SBA-15 with $\mathrm{pH}$ adjustment}

The method using $\mathrm{pH}$ adjustment was adapted from the literature ${ }^{12}$. In this procedure aluminum hydroxide $\left(\mathrm{Al}(\mathrm{OH})_{3}\right)$ was used as the source of $\mathrm{Al}$. The composition of the synthesis gel was set to be: $0.172 \mathrm{SiO}_{2}: \mathrm{x} \mathrm{Al}_{2} \mathrm{O}_{3}: 0.003$ P123: $0.483 \mathrm{HCl}: 31.766 \mathrm{H}_{2} \mathrm{O}$ : y NaF. The $\mathrm{Si} / \mathrm{Al}$ ratios studied were 5 and 15, with $\mathrm{x}$ (amount of $\mathrm{Al}_{2} \mathrm{O}_{3}$ ) equal to 0.017 and 0.005 , respectively. The y values used were 0.001 and 0.003 equivalent to a $\mathrm{Si} / \mathrm{F}$ ratio $=120$ and 61, respectively. Initially, Pluronic P123 was added to a solution containing water, $\mathrm{HCl}$ and $\mathrm{NaF}$. This solution was kept under stirring at $35^{\circ} \mathrm{C}$ until the complete dissolution of the polymer. Then, 
the TEOS was added. The solution was stirred at $45^{\circ} \mathrm{C}$ for 30 minutes, and $\mathrm{Al}(\mathrm{OH})_{3}$ was added thereafter. This mixture was kept under stirring at $45^{\circ} \mathrm{C}$ for $1.5 \mathrm{~h}$, and the mixture was then separated into 3 groups, placed in Teflon autoclaves and brought to the thermostatized bath for an initial aging of $24 \mathrm{~h}$ at $90^{\circ} \mathrm{C}$. Then the $\mathrm{pH}$ of each group was modified to 2,4 , and 8 with addition of $\mathrm{NH}_{4} \mathrm{OH}$ solution $\left(5 \mathrm{~mol}\right.$. $\left.\mathrm{L}^{-1}\right)$. After adjusting to a certain $\mathrm{pH}$, the samples continued aging for $24 \mathrm{~h}$ at $90^{\circ} \mathrm{C}$. Table 1 shows a summary of the synthesis conditions studied and the nomenclature of the samples obtained in each experiment. The product of each synthesis was filtered and washed with distilled water, dried and calcined at $600^{\circ} \mathrm{C}$ at air atmosphere for $5 \mathrm{~h}$, with a heating ramp of $2^{\circ} \mathrm{C} \mathrm{min}^{-1}$.

\subsection{Characterization of materials}

The synthesized materials were characterized by X-ray diffraction in a Bruker D2 Phaser apparatus using $\mathrm{CuK} \alpha$ radiation $(\lambda=1.54 \AA)$ with a Ni filter, a current of $10 \mathrm{~mA}$, a voltage of $30 \mathrm{kV}$, and a Lynxeye detector. All measurements were made at low angle, in the $2 \theta$ range from 0.6 to $5^{\circ}$; For this, a slit was used, which has an aperture of approximately $0.1 \mathrm{~mm}$ and a pitch of $0.01^{\circ}$. The hexagonal lattice parameter $\left(\mathrm{a}_{0}\right)$ of each sample were determined from the interplanar distances (d) in the plane (100) obtained in the X-ray diffractograms. The hexagonal lattice parameter values $\left(\mathrm{a}_{0}\right)$ were calculated using equation 01 , as shown below:

$$
a_{0}=\frac{2 d_{(100)}}{\sqrt{3}}
$$

X-ray diffraction spectroscopy (EDX) measurements were performed under an air atmosphere, using EDX-720 equipment, with a scan of Titanium (U) and Uranium (U) analytes and a $50 \mathrm{KV}$ current, and another scan of Sodium

Table 1. Summary of synthesis conditions with $\mathrm{pH}$ adjustment of Al/SBA15 and sample nomenclature.

\begin{tabular}{lccc}
\hline $\begin{array}{l}\text { Molar ratio } \\
\text { Si / Al of } \\
\begin{array}{l}\text { Reaction } \\
\text { Mixture }\end{array}\end{array}$ & $\begin{array}{c}\text { Molar ratio } \\
\mathrm{Si} / \mathrm{F}\end{array}$ & $\begin{array}{c}\text { Adjusted } \mathrm{pH} \\
\text { Value }\end{array}$ & Sample \\
\hline & & 2 & $5 \mathrm{AlS} 61 / \mathrm{pH} 2$ \\
& 61 & 4 & $5 \mathrm{AlS} 61 / \mathrm{pH} 4$ \\
5 & & 8 & $5 \mathrm{AlS} 61 / \mathrm{pH} 8$ \\
& & 2 & $5 \mathrm{AlS} 120 / \mathrm{pH} 2$ \\
& 120 & 4 & $5 \mathrm{AlS} 120 / \mathrm{pH} 4$ \\
& & 8 & $5 \mathrm{AlS} 120 / \mathrm{pH} 8$ \\
& & 2 & $15 \mathrm{AlS} 61 / \mathrm{pH} 2$ \\
& 61 & 4 & $15 \mathrm{AlS} 61 / \mathrm{pH} 4$ \\
& & 8 & $15 \mathrm{AlS} 61 / \mathrm{pH} 8$ \\
& & 2 & $15 \mathrm{AlS} 120 / \mathrm{pH} 2$ \\
& & 4 & $15 \mathrm{AlS} 120 / \mathrm{pH} 4$ \\
& & 8 & $15 \mathrm{AlS} 120 / \mathrm{pH} 8$ \\
\hline
\end{tabular}

(Na) to Scandium $(\mathrm{Sc})$ with a current of $15 \mathrm{KV}$. The adsorption and desorption isotherms of $\mathrm{N}_{2}$ were obtained in a NOVA 1200 model of Quantachrome Instruments. The samples were pre-treated at $300{ }^{\circ} \mathrm{C}$ for $3 \mathrm{~h}$, and the relative pressure range was from 0.05 to 1.0 . The obtained results were treated, and the specified areas were obtained using the BET method (Brunauer, Emmett and Teller) and alpha-plot method ${ }^{13}$ to calculate volume of micropores in the range of $0.1<\mathrm{p} / \mathrm{p} 0<0.3$. For the determination of the distribution and pore diameter, the method proposed by Barrett, Joyner, and Halenda, known as BJH, was used. From the pore diameter values $\mathrm{D}_{\mathrm{p}}$, it is possible to calculate the wall thickness of the pores (wt), using equation 02 , as show below:

$$
w t=a_{0}-D_{p}
$$

Analyses of ${ }^{27} \mathrm{Al}$ MAS NMR were performed on a Bruker AV-400-WB spectrometer at room temperature operated at $104.20 \mathrm{MHz}$, with a rotational speed of $14.8 \mathrm{kHz}$ and an acquisition time of $0.02 \mathrm{~s}$.

\subsection{Catalytic test}

The catalytic tests were performed using $30 \mathrm{mg}$ of sample and a fixed bed reactor, under atmospheric pressure and 250 ${ }^{\circ} \mathrm{C}$. Before the reaction, the catalysts were first activated under nitrogen flow for 1 hour at atmospheric pressure. After the activation, the catalysts were submitted to a mixture containing $\mathrm{N}_{2}$ and ethanol vapor (a total of $25 \mathrm{~mL} / \mathrm{min}$ ) that passed through the reactor. The mixture was established by flowing $\mathrm{N}_{2}$ through the saturator containing ethanol at $25^{\circ} \mathrm{C}$. Reaction products were analyzed by gas chromatography (GC - Clarus 680, Perkin Elmer) using the flame ionization detector (FID) and equipped with an Equity -5 (30 m x $0.25 \mathrm{~mm} \times 0.25 \mu \mathrm{m}$ ) capillary column.

The conversion (equation 03 ) of ethanol and selectivity (equation 04) were calculated as follows ( $\mathrm{A}$ is peak area):

$\% X($ ethanol $)=\frac{A\left(\text { Ethanol }_{\text {Initial }}\right)-A\left(\text { Ethanol }_{\text {Final }}\right)}{A\left(\text { Ethanol }_{\text {Initial }}\right)} \times 100$

$\% S\left(\right.$ Product $\left._{i}\right)=\frac{A\left(\text { Product }_{i}\right)}{\sum A\left(\text { Product }_{i}\right)} \times 100$

For recycling experiments, the solid used in a first run was pre-treated again in $\mathrm{N}_{2}\left(25 \mathrm{~mL} \mathrm{~min}^{-1}\right)$ at $350{ }^{\circ} \mathrm{C}$ for $1 \mathrm{~h}$ after each run and reused in the ethanol conversion at $250^{\circ} \mathrm{C}$ for $4 \mathrm{~h}$, as described for the fresh solids.

\section{Results}

Figure 1 shows the $\mathrm{X}$-ray diffractogram of the $\mathrm{Al} / \mathrm{SBA}-15$ samples synthesized by the direct synthesis method, where reflections referring to the planes (100), (110) and (200) can be observed, indicating a hexagonal mesopore structure. 
Diffractograms of the samples obtained using $\mathrm{pH}$ adjustment and varying the amount of $\mathrm{Si} / \mathrm{F}$ and $\mathrm{Si} / \mathrm{Al}$ are shown in Figure 2. When the samples synthesized by $\mathrm{pH}$ adjustment are compared to each other, a significant decrease in the first reflection d100 is observed in the synthesis products with a $\mathrm{pH}=8$ and $\mathrm{Si} / \mathrm{F}$ ratio $=61$, independent of the $\mathrm{Si} / \mathrm{Al}$ ratio. When the amount of $\mathrm{NaF}$ added is lower

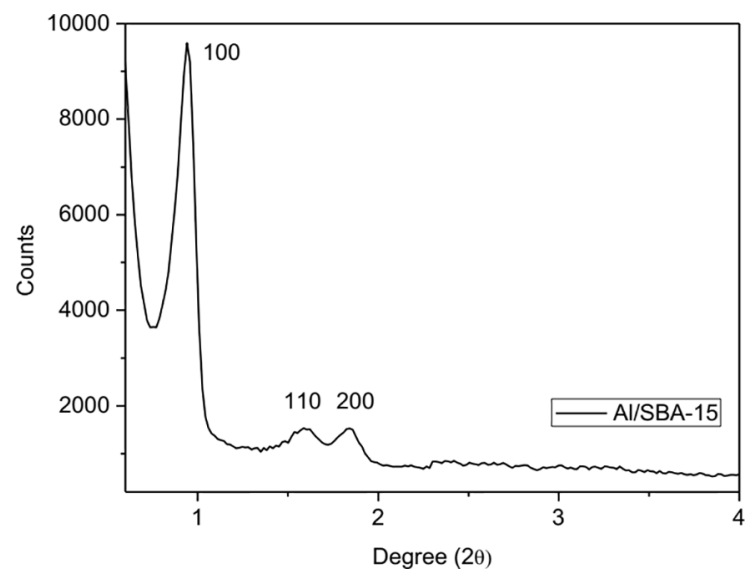

Figure 1. Diffractogram of calcined Al/SBA-15 sample with a $\mathrm{Si} /$ Al ratio of 5 obtained by direct synthesis.

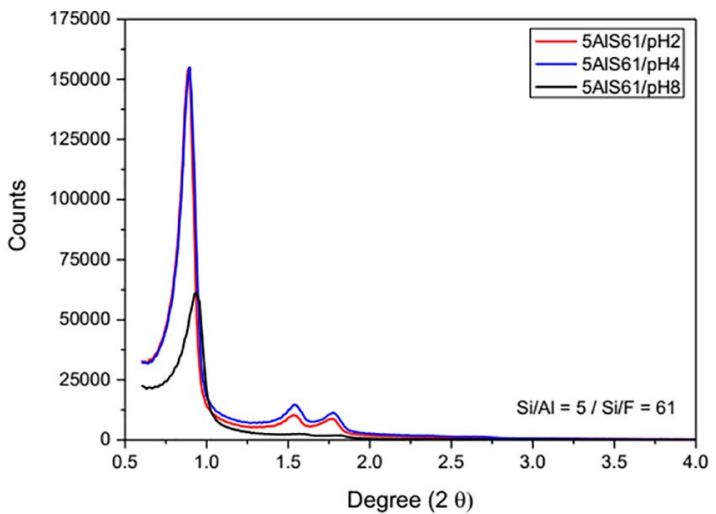

(a)

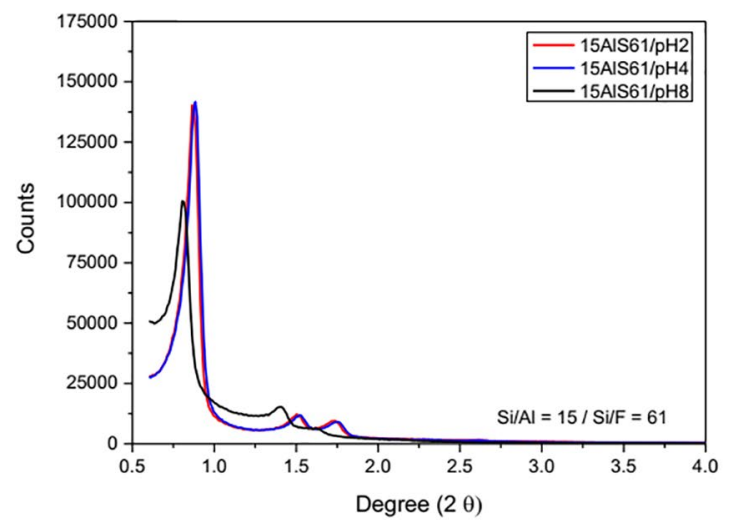

(c)
$(\mathrm{Si} / \mathrm{F}=120)$, there is an improvement in the organization of materials after adjusting the $\mathrm{pH}$ to 4 and 8 .

Figure 3 shows the $\mathrm{N}_{2}$ adsorption isotherms for $\mathrm{Al} /$ SBA-15 synthesized by the direct route and the products obtained through synthesis with $\mathrm{pH}$ adjustment.

All isotherms shown in Figure 3 can be classified as type IV, which is characteristic of mesoporous materials that include SBA-15 type materials. These materials, when well organized, have $\mathrm{H} 1$ type hysteresis, which is associated with the presence of cylindrical pores. When the hysteresis inclination is smaller, the obtained pores are more uniforms ${ }^{14,15}$. The samples 5A1S61/pH8, 15A1S120/pH8 and 15A1S120/ pH8 presented type $\mathrm{H} 2$ (b) type hysteresis, which is related to mesoporous materials with sample partial pore block ${ }^{14}$. Figure 4 shows the pore distribution of the samples by BJH method. Table 2 shows data related to the textural properties of the synthesized Al/SBA-15 materials obtained from the isotherm data and the ratio $\mathrm{Si} / \mathrm{Al}$ calculate from the data of the EDX analysis.

All the materials in which the aluminum was incorporated presented a smaller specific area compared to pure silicon materials (without effective aluminum insertion). The decrease in the specific area values is mainly due to the

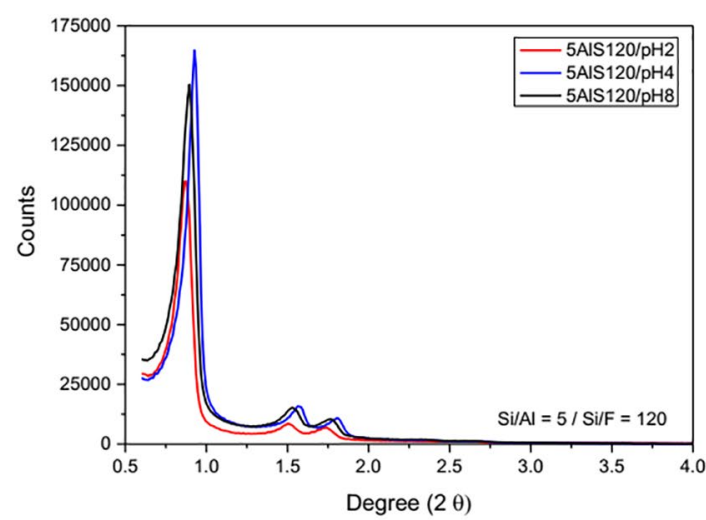

(b)

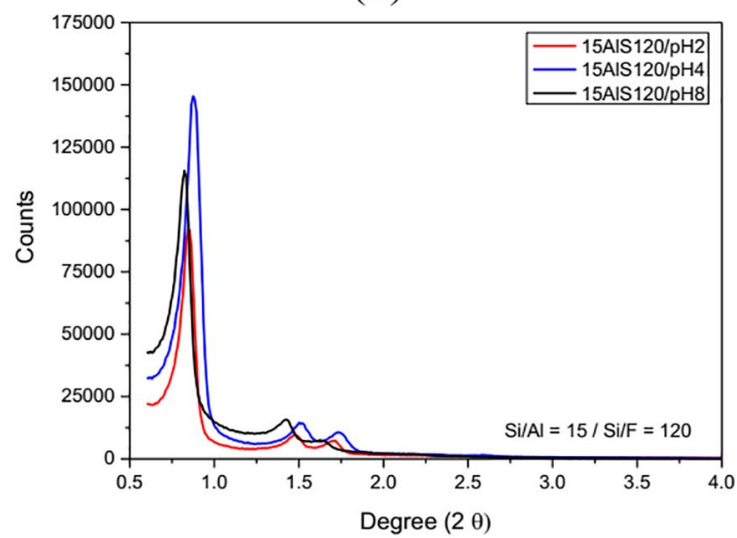

(d)

Figure 2. Diffractograms of the calcined samples synthesized by $\mathrm{pH}$ adjustment. Samples are divided based on the ratios of $\mathrm{Si} / \mathrm{Al}$ and $\mathrm{Si} / \mathrm{F}$ : (a) Samples synthesized with $\mathrm{Si} / \mathrm{Al}=5$ and $\mathrm{Si} / \mathrm{F}=61$; (b) Samples synthesized with $\mathrm{Si} / \mathrm{Al}=5$ and $\mathrm{Si} / \mathrm{F}=120$; (c) Samples synthesized with $\mathrm{Si} / \mathrm{Al}=15$ and $\mathrm{Si} / \mathrm{F}=61 ;$ (d) Samples synthesized with $\mathrm{Si} / \mathrm{Al}=15$ and $\mathrm{Si} / \mathrm{F}=120$. 


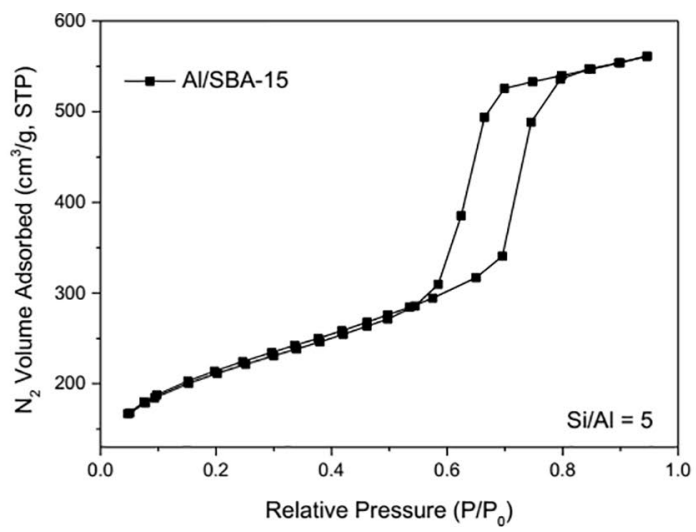

(a)

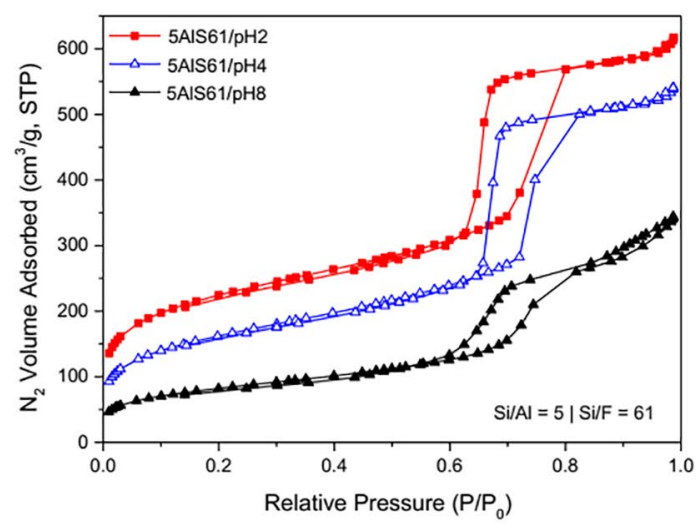

(b)

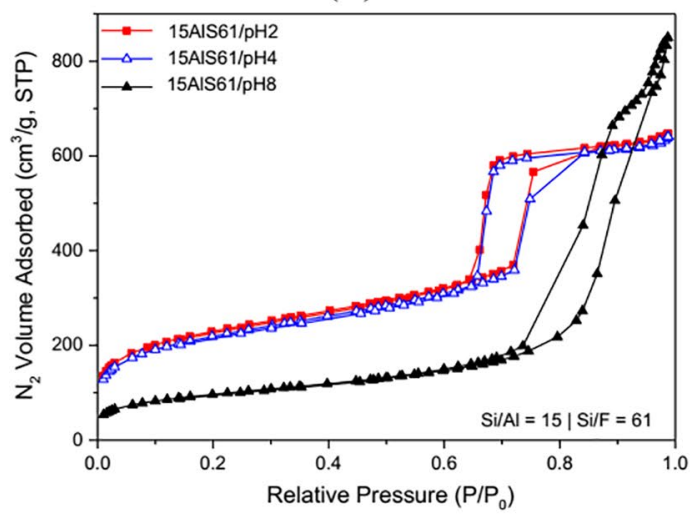

(d)

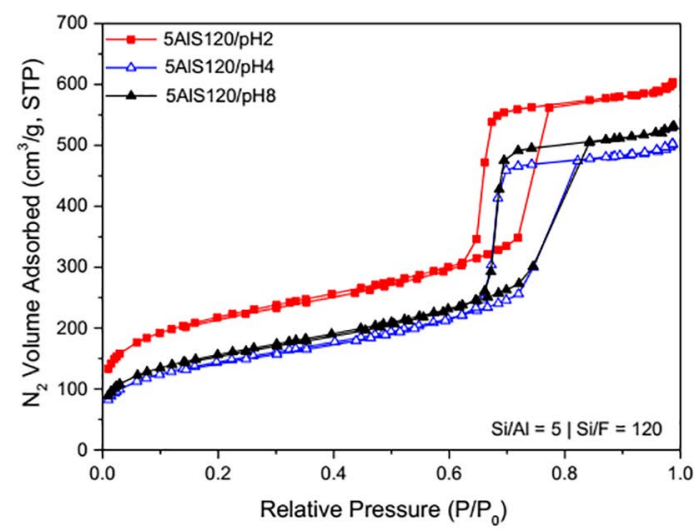

(c)

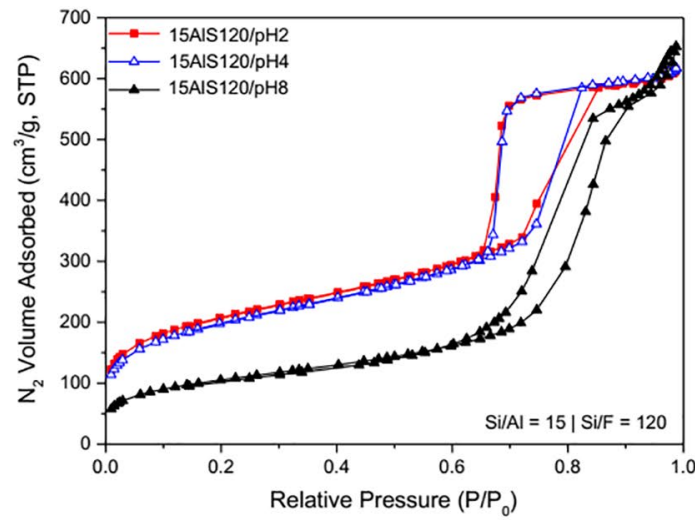

(e)

Figure 3. Isotherms of adsorption of $\mathrm{N} 2$ of the $\mathrm{Al} / \mathrm{SBA}-15$ sample and samples obtained by synthesis with $\mathrm{pH}$ adjustment. The samples are divided as follows: (a) Sample synthesized without $\mathrm{pH}$ adjustment; (b) Samples synthesized with $\mathrm{Si} / \mathrm{Al}=5$ and Si/F $=61$; (c) Samples synthesized with $\mathrm{Si} / \mathrm{Al}=5$ and $\mathrm{Si} / \mathrm{F}=120$; (d) Samples synthesized with $\mathrm{Si} / \mathrm{Al}=15$ and $\mathrm{Si} / \mathrm{F}=61$; (e) Samples synthesized with $\mathrm{Si} / \mathrm{Al}=15$ and $\mathrm{Si} / \mathrm{F}=120$.

reduced contribution of the micropores. The reduction of micropore volume was significant in samples $5 \mathrm{AlS} 61 / \mathrm{pH} 4$, 5AlS61/pH8, 5AlS120/pH4, 5AlS120/pH8, 15AlS61/pH8 and $15 \mathrm{AlS} 120 / \mathrm{pH} 8$. Samples $15 \mathrm{AlS} 61 / \mathrm{pH} 2$ and $15 \mathrm{AlS} 120 /$ $\mathrm{pH} 2$ presented higher values of specific area and volume of micropores than samples $15 \mathrm{AlS} 61 / \mathrm{pH} 4$ and $15 \mathrm{AlS} 120 / \mathrm{pH} 4$ (Table 2) which no incorporation of $\mathrm{Al}$ occurred.
Although the $\mathrm{pH}$ has a large influence on the insertion of aluminum to the mesoporous material SBA- 15 , the incorporated aluminum can be either coordinated in a tetrahedral form and, thus, present in the structural network of the material or in a hexacoordinate form, where it would not be present in the structural network but on the surface. Figure 5 shows the NMR spectra of the samples that contained $\mathrm{Al}$ in their composition. 
(a)

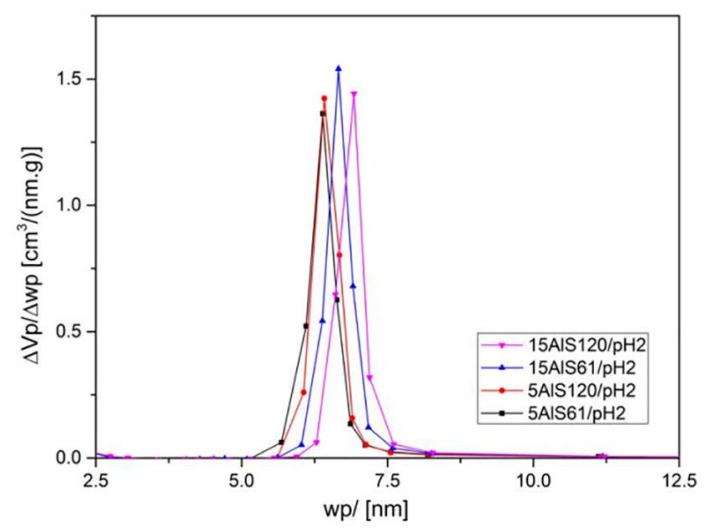

(b)

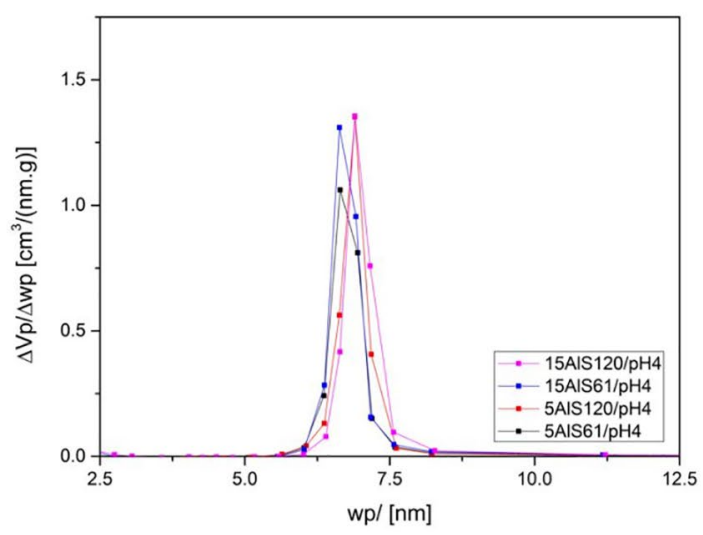

(c)

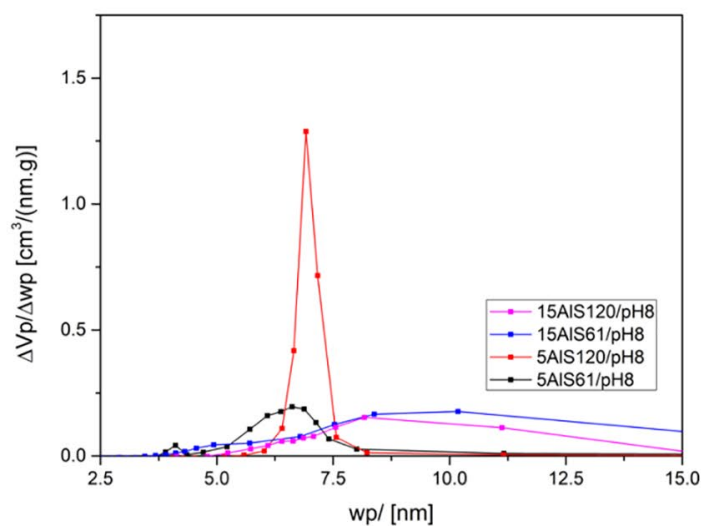

Figure 4. Pore distribution by BJH method for the samples obtained by synthesis with $\mathrm{pH}$ adjustment: (a) $\mathrm{pH}=2.0$; (b) $\mathrm{pH}=4.0$ and (c) $\mathrm{pH}=8.0$

The ${ }^{27} \mathrm{Al}$ MAS NMR spectra of all samples analyzed show two peaks at approximately $50 \mathrm{ppm}$ and $0 \mathrm{ppm}$ (Figure 5). Signals in these regions are due to the presence of $\mathrm{Al}$ tetrahedrally coordinated (Al IV) and Al hexacoordinated (Al VI), respectively ${ }^{7,16}$. Figure 5 (a) and (b) refer to the spectra of samples synthesized with a $\mathrm{Si} / \mathrm{Al}$ ratio of 5 and varying $\mathrm{Si} / \mathrm{F}$ ratios. The two spectra in Figure 5 (a) are of the obtained products, starting from a ratio $\mathrm{Si} / \mathrm{F}=61$, in which the final $\mathrm{Si} / \mathrm{Al}$ ratio of the material obtained was 9 for the sample 51AlS61/pH4 and 4 for the sample 5AlS61/ $\mathrm{pH} 8$ (Table 2). The spectrum of the 5AlS61/pH8 1AlS15-G3 sample (Figure 5a) shows a distribution of $\mathrm{Al}$ species, including hexacoordinated (Al VI), pentacoordinated (Al V) and tetracoordinated (Al IV) aluminum species. Figure 5 (b) shows the spectra of samples synthesized with a $\mathrm{Si} / \mathrm{F}$ ratio of 120 and a smaller amount of $\mathrm{NaF}$ in the reaction. In these samples, the abundance of pentacoordinated aluminum is very small, and the amount of $\mathrm{Al}$ is very close, as seen in Table 2. The spectra of samples 15AlS61/pH815-G3 and 15AlS120/ $\mathrm{pH} 8$ (Figure 5c) show that the $\mathrm{Al}$ species present are $\mathrm{Al} \mathrm{V}$, $\mathrm{Al}$ IV and Al VI type. Both syntheses were performed with $\mathrm{pH}$ adjustment to 8, a Si/F ratio of 61 for sample 15AlS61/ pH8 and of 120 for sample 15AlS120/pH8, corresponding $\mathrm{Si} / \mathrm{Al}$ ratios for the final products of 11 and 13 , respectively. The lower Si/F ratio employed in sample 15AlS120/pH8 contributed to a greater abundance of tetracoordinated $\mathrm{Al}$ compared to octahedral aluminum.

The catalytic conversion of ethanol is used, as a model reaction, to indicate the acid-base character of several catalysts. The results obtained for the tests using Al/SBA-15 samples at $250{ }^{\circ} \mathrm{C}$ are shown in Figure 6 (a). Considering the catalysts obtained, we have the following order for the catalytic conversion considering an average of all points during the $4 \mathrm{~h}$ of reaction: SBA-15 $<15 \mathrm{AlS} 120 / \mathrm{pH} 8<$ 15AlS61/pH8 $<5$ AlS120/pH4 $<5$ AlS120/pH8 $<5$ AlS61/ pH8. Figure 6 (b) shows the selectivity of the products obtained during ethanol dehydration.

The products obtained in the reaction were ethylene and diethyl ether. Therefore, the catalytic reaction occurred by acidic sites via intramolecular and intermolecular dehydration reactions, respectively ${ }^{17}$.

The best conversion and stability for the 5AlS61/pH8 catalyst make the study of reuse interesting. The four catalytic tests are showed in Figure 7. These results clearly presented that for the 5AlS61/pH8 sample no significant decrease in the catalytic conversion and selectivity were observed after the second recycling test. However, the ethanol conversion achieved over $23 \%$ after the fourth reuse test, but the ethylene and diethyl ether selectivity is similar to the first experiment, virtually no difference between them.

\section{Discussion}

All the samples obtained in this study show characteristic diffractograms of the SBA-15 type material. In the diffractograms shown in Figures 1 and 2, reflections referring to planes (100), (110) and (200) can be observed, indicating that the material formed is well organized. This demonstrates that with this method an aging step with $\mathrm{pH}$ between 1 and 1.5 
Table 2. Textural properties of Al/SBA-15 materials synthesized by direct route and samples obtained by $\mathrm{pH}$ adjustment.

\begin{tabular}{|c|c|c|c|c|c|c|c|c|c|}
\hline Sample & $\begin{array}{l}\text { SBET } \\
\left(\mathrm{m}^{2} / \mathrm{g}\right)\end{array}$ & $\begin{array}{c}\mathrm{Vm} \\
\left(\mathrm{cm}^{3} / \mathrm{g}\right)\end{array}$ & $\begin{array}{c}\text { Vtp } \\
\left(\mathrm{cm}^{3} / \mathrm{g}\right)\end{array}$ & $\mathrm{Sm}\left(\mathrm{m}^{2} / \mathrm{g}\right)$ & $\mathrm{Dp}(\mathrm{nm})$ & $\mathrm{d} 100(\mathrm{~nm})$ & $\mathrm{a}_{0}(\mathrm{~nm})$ & wt (nm) & $\mathrm{Si} / \mathrm{Al}$ \\
\hline $\mathrm{Al} / \mathrm{SBA}-15$ & 765 & 0.09 & 0.87 & 200 & 6.3 & 9.73 & 11.23 & 4.9 & - \\
\hline 5A1S61/pH2 & 810 & 0.08 & 0.94 & 175 & 6.4 & 9.86 & 11.38 & 5.0 & - \\
\hline 5AlS61/pH4 & 585 & 0.03 & 0.82 & 81 & 6.6 & 9.89 & 11.42 & 4.8 & 9 \\
\hline 5AlS61/pH8 & 300 & 0.01 & 0.51 & 27 & $-\mathrm{a}$ & 9.44 & 10.90 & -a & 4 \\
\hline 5AlS120/pH2 & 780 & 0.09 & 0.92 & 211 & 6.4 & 10.14 & 11.71 & 5.3 & - \\
\hline 5AlS120/pH4 & 505 & 0.02 & 0.77 & 40 & 6.9 & 9.54 & 11.01 & 4.1 & 7 \\
\hline 5AlS120/pH8 & 564 & 0.03 & 0.81 & 68 & 6.9 & 9.87 & 11.40 & 4.5 & 9 \\
\hline 15AlS61/pH2 & 825 & 0.07 & 0.99 & 169 & 6.7 & 10.20 & 11.78 & 5.1 & - \\
\hline 15AlS61/pH4 & 795 & 0.06 & 0.98 & 164 & 6.6 & 9.97 & 11.51 & 4.9 & - \\
\hline 15AlS61/pH8 & 350 & 0.01 & 1.17 & 28 & $-\mathrm{a}$ & 10.95 & 12.64 & -a & 11 \\
\hline $\begin{array}{l}\text { 15AlS120/ } \\
\mathrm{pH} 2\end{array}$ & 750 & 0.06 & 0.94 & 156 & 6.9 & 10.42 & 12.03 & 5.1 & - \\
\hline $\begin{array}{l}\text { 15AlS120/ } \\
\text { pH4 }\end{array}$ & 710 & 0.05 & 0.94 & 111 & 6.9 & 10.08 & 11.64 & 4.7 & - \\
\hline $\begin{array}{l}\text { 15AlS120/ } \\
\text { pH8 }\end{array}$ & 380 & 0.01 & 0.96 & 32 & -a & 10.72 & 12.38 & -a & 13 \\
\hline
\end{tabular}

a - These materials presented a hysteresis profile related to non-uniform pores, and only the pore diameter was calculated for materials with cylindrical pore profile; wt - Mesopore wall thickness; Dp - Pore diameter, calculated using the BJH method; d100 - Spacing between planes (100); a 0 - hexagonal lattice parameter; Vm - Micropore volume; Vtp - total pore volume; Sm - surface of the micropores was calculate subtracting the BET area value from the value of St (sum of surface values of primary mesopores and external surface) and $\mathrm{S}_{\mathrm{BET}}-$ Specific area calculated by method (Brunauer-Emmett-Teller $\left.-\mathrm{BET}\right)$ ) in the $\mathrm{p} / \mathrm{p}_{0}$ range $=0.02-0.20$.

a)

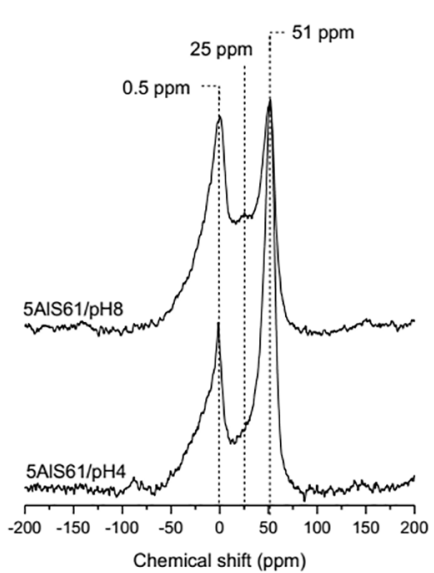

b)

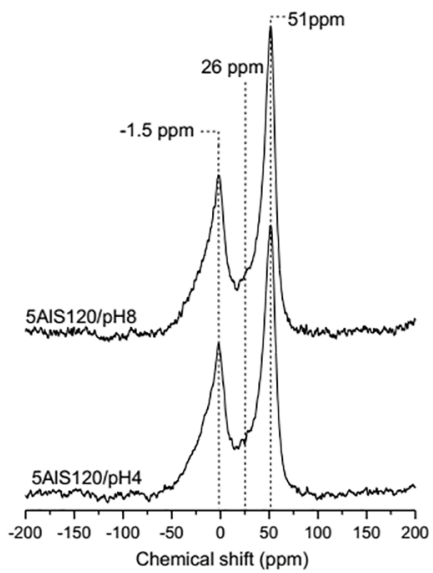

c)

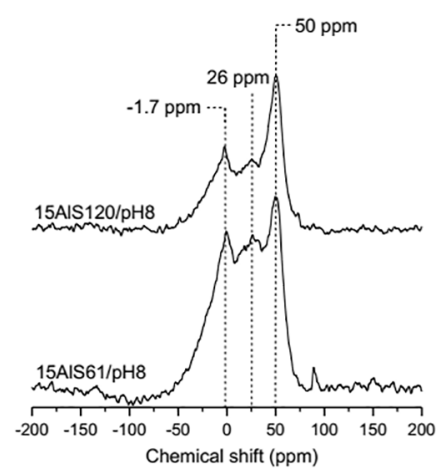

Figure 5. ${ }^{27} \mathrm{Al}$ MAS NMR spectra of a) $5 \mathrm{AlS} 61 / \mathrm{pH} 8$ and $5 \mathrm{AlS} 61 / \mathrm{pH} 4$, ratio $\mathrm{Si} / \mathrm{F}=61$; b) $5 \mathrm{AlS} 120 / \mathrm{pH} 4$ and $5 \mathrm{AlS} 120 / \mathrm{pH} 8, \mathrm{ratio} \mathrm{Si} / \mathrm{F}=$ $120 ;$ c) $15 \mathrm{AlS} 61 / \mathrm{pH} 8$, ratio $\mathrm{Si} / \mathrm{F}=61$ and $15 \mathrm{AlS120} / \mathrm{pH} 8$, ratio $\mathrm{Si} / \mathrm{F}=120$.

is required for the formation of the material. This is because the solubilization of the copolymer in aqueous medium occurs via the association of the water molecules with the hydrophilic parts of the polyethylene oxide (PEO) in P123, and at a low $\mathrm{pH}$, the oxygen atom on the polyethylene chains can be protonated. $\mathrm{HCl}$ also acts as an acid catalyst for the hydrolysis of TEOS; because the isoelectric point of the silica is at $\mathrm{pH}<2$, the silica species can be positively charged and consequently hydrolyzed into cationic species ${ }^{8,18}$. In this study, $\mathrm{Si} / \mathrm{F}$ ratios of 120 and $61(0.03$ and $0.06 \mathrm{~g}$ of NaF, respectively) were used because a further increase in the amount of fluorine will not promote the formation of SBA15. $\mathrm{Si} / \mathrm{F}$ molar ratios lower than 48 promote the formation of amorphous materials ${ }^{10}$. The presence of fluoride ions $\left(\mathrm{F}^{-}\right)$ during the synthesis affects the degree of polymerization of the synthesis and increases the proportion of $\mathrm{SiO}_{4}$ present in the synthesis gel ${ }^{19}$. Therefore, the addition of small amounts of $\mathrm{NaF}$ helps decrease the synthesis time, since it increases 
a)

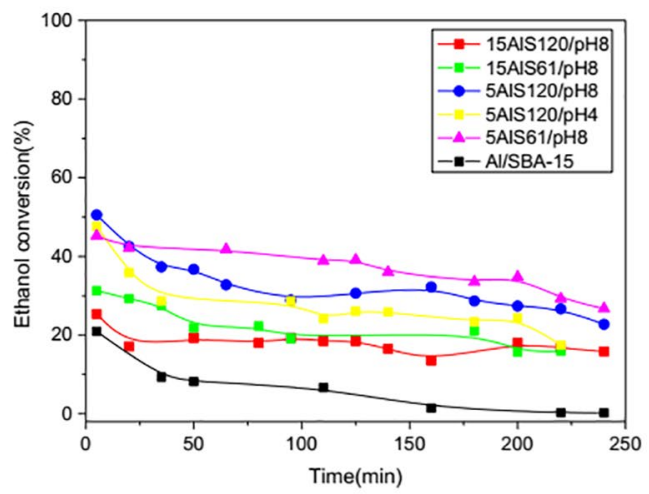

b)

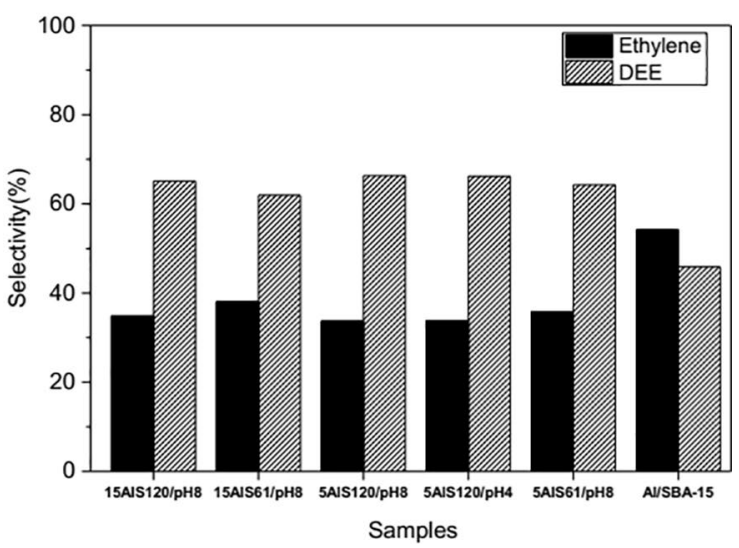

Figure 6. Graphics of ethanol conversion and product selectivity in a) ethanol conversion as a function of time at $250^{\circ} \mathrm{C}$ of samples and b) product selectivity at $250{ }^{\circ} \mathrm{C}$.

the rates of hydrolysis and condensation of the silicon. The presence of inorganic salts increases the interaction between silicate species and nonionic block copolymers ${ }^{24}$.

Aluminum was not detected in the sample Al/SBA-15 that was synthesized without $\mathrm{pH}$ adjustment (Table 2). All of the samples synthesized with $\mathrm{pH}$ adjustment to 8 contained aluminum in their composition. At $\mathrm{pH} 8$, there $\operatorname{are~} \mathrm{Al}(\mathrm{OH})_{4}$ species that can be subjected to further condensation with the silanol groups on the surface of the preformed mesostructured material; in this way, the aluminum atoms are grafted onto the structure ${ }^{12}$. In the samples synthesized with $\mathrm{pH}$ adjusted to 4 , only samples with a ratio of $\mathrm{Si} / \mathrm{Al}=5$ had incorporated aluminum. The step of adjusting the $\mathrm{pH}$ to values above 4 has a fundamental role in producing materials of the SBA15 type with aluminum.

All the materials in which the aluminum was incorporated presented a smaller specific area compared to pure silicon materials (without effective aluminum insertion). The decrease in the specific area is mainly due to the reduced contribution of the micropores. For samples $5 \mathrm{AlS} 61 / \mathrm{pH} 4$, 5AlS61/pH8, 5AlS120/pH4, 5AlS120/pH8, 15AlS61/pH8
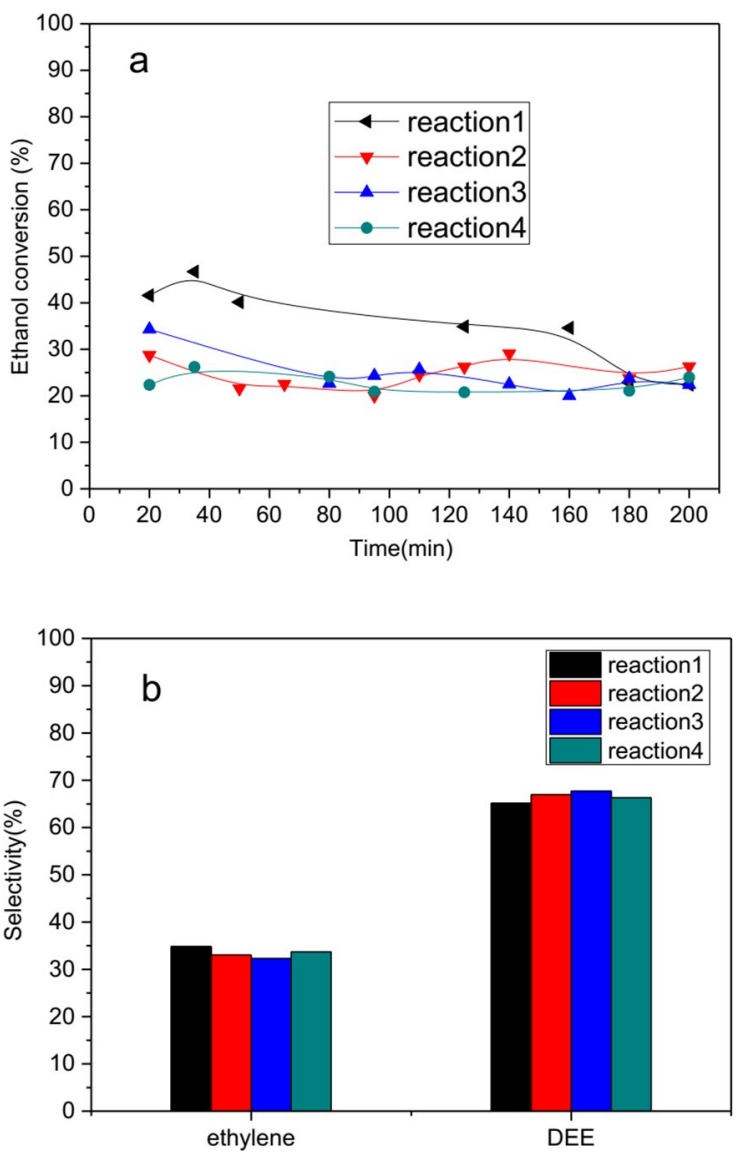

Figure 7. Catalyst reusability for the sample 5AlS61/pH8. a) ethanol conversion as a function of time at $250{ }^{\circ} \mathrm{C}$ and b) product selectivity at $250^{\circ} \mathrm{C}$.

and $15 \mathrm{AlS} 120 / \mathrm{pH} 8$, the reduction of micropore volume was significant (Table 2). Similar behavior was observed by Zucal et al. ${ }^{20}$. However, in their work, the aluminum insertion was done during the post-synthesis treatment. In our study, the syntheses were performed at $90{ }^{\circ} \mathrm{C}$, which favors the formation of high microporosity in the walls of the material and few interconnections between the pores ${ }^{21}$. The aluminum insertion gradually fills the micropores present in the walls of the mesoporous channels, and the surface of these channels becomes more smooth and uniform without the presence of microporosity ${ }^{20}$. In fact, there are significant variations in the specific areas following the aluminum insertion, but the diameter of the mesopores does not vary significantly (BJH method underestimate the pore diameter, but for comparative purposes can be used ${ }^{22}$ ), which is a strong evidence for a decrease in microporosity to maintain the diameter of the mesopores. Samples $15 \mathrm{AlS} 61 / \mathrm{pH} 2$ and $15 \mathrm{AlS} 120 / \mathrm{pH} 2$ presented higher values of specific area and volumes of micropores compared to samples 15AlS61/pH4 and 15AlS120/pH4, respectively (Table 2). In both 15AlS61/ $\mathrm{pH} 4$ and 15AlS120/pH4 samples, no incorporation of $\mathrm{Al}$ occurred. It was expected that the higher amount of $\mathrm{NaF}$ added in the synthesis would produce materials with lower 
volumes of micropores, however, this was not observed because samples $15 \mathrm{AlS} 120 / \mathrm{pH} 2$ and $15 \mathrm{AlS} 120 / \mathrm{pH} 4$ had the lowest volume values of micropores compared with samples $15 \mathrm{AlS} 61 / \mathrm{pH} 2$ and $15 \mathrm{AlS} 61 / \mathrm{pH} 4$. The samples $15 \mathrm{AlS} 120 / \mathrm{pH} 2$ and $15 \mathrm{AlS} 120 / \mathrm{pH} 4$ were synthesized with a $\mathrm{Si} / \mathrm{F}$ ratio $=120$ and, therefore, fewer fluoride ions than the samples with a $\mathrm{Si} / \mathrm{F}$ ratio $=61$. In this study, because the amount of $\mathrm{NaF}$ added was small, the reduction in volume values of micropores can be mostly attributed to the variation in the incorporated aluminum.

The addition of $\mathrm{NaF}$ implies the presence of $\mathrm{Na}^{+}$and $\mathrm{F}^{-}$ions in the reaction medium. The synthesis of SBA-15 type materials using sodium silicate has already been investigated, and comparing the results with those obtained with syntheses using TEOS showed a small variation in the thickness of the silica wall ${ }^{23}$. In this case, the fluoride ions in the synthesis can have as much effect as a catalyst in the processes of hydrolysis and condensation on the mechanism for formation of the mesoporous structure in the presence of Al. One of the proposed mechanisms for the formation of SBA-15 is based on the electrostatic interactions between the protonated polypropylene groups (belonging to P123) and the positively charged inorganic network, and this interaction is mediated by chloride ions in solution ${ }^{24}$. When fluoride ions are added, in addition to accelerating the polymerization process, they may contribute to the existence of fewer defects in the network ( $\mathrm{Si}-\mathrm{OH}$ groups). As the synthesis process occurs through two steps, the inorganic silica network is already preformed, but $\mathrm{Al}$ is not incorporated. When $\mathrm{pH}$ is modified, Al incorporation occurs via surface in $\mathrm{Si}-\mathrm{OH}$ groups, and many of these $\mathrm{OH}^{-}$groups may be replaced by fluoride ions. When the amount of aluminum added in the synthesis is smaller, the incorporation of aluminum would occur in a non-homogeneous way on the surface of the micropores, which would justify the presence of blocked or partially blocked mesopores, as indicated by the $\mathrm{N}_{2}$ adsorption analysis for samples $15 \mathrm{AlS} 61 / \mathrm{pH} 8,15 \mathrm{AlS120/}$ $\mathrm{pH} 8$, and $5 \mathrm{AlS} 61 / \mathrm{pH} 8$.

In relation to the catalytic tests, the pure silica SBA-15 sample showed very low activity due to the presence of only silanol $(\mathrm{Si}-\mathrm{OH})$ groups, which are very weak acidic sites. According to microcalorimetric studies of ammonia desorption by Kumaran et al. ${ }^{25}$ and Zheng et al. ${ }^{26}$, the number of acidic sites and the acid strength of SBA-15 are very low or almost inactive compared with those of Si-SBA-15. The aluminum insertion in the mesoporous structure increased the catalytic activity because there was a gradual increase in the ethanol conversion with the decrease in the $\mathrm{Si} / \mathrm{Al}$ ratio, consequently, an increase in the amount of Al. The materials with high $\mathrm{Al}$ content have a decrease in area because of microporous blockage. As the ethanol molecule can diffuse in the SBA15 structure without restriction, the catalytic activity was measure by acidity $\mathrm{Al}$ content. It is already well known and documented that the substitution of $\mathrm{Al}$ in structures of pure silicon generates Bronsted acidity ${ }^{1,27}$. Studies carried out by Kumaran et al. ${ }^{25}$ and YUN et al. ${ }^{28}$ also observed an increase in the acid character of Al-SBA-15 with an increasing amount of Al. The material 5AlS61/pH8 showed a better catalytic performance. In all materials, the conversion values were not stable. This phenomenon may be associated with a catalytic deactivation by coke formation because a large amount of the $\mathrm{Al}$ is present in the inner part of the channels, hexacoordenated and pentacoordinated.

The higher selectivity for diethyl ether compared to ethylene is related to the thermodynamic aspects, since the dehydration of ethanol to diethyl ether is an exothermic process which is favored at low temperatures $\left(250^{\circ} \mathrm{C}\right)$. Probably, the ethanol dehydration occurs mostly through parallel routes, at moderate temperatures $\left(250^{\circ} \mathrm{C}\right)$, producing ethylene by the decomposition of chemisorbed ethanol molecules $\left(\mathrm{C}_{2} \mathrm{H}_{5} \mathrm{OH}_{2}^{+}\right)$and formation of DEE by the reaction between chemisorbed and physisorbed ethanol molecules on the catalyst surface ${ }^{29,30}$. The presence of acetaldehyde, a product of the ethanol dehydrogenation, was not observed, indicating that the solids do not have basic sites.

The results of recycle tests (Figure 7) show that the catalytic conversion and the selectivity did not decrease dramatically during the reuse run, considering that no special treatment (reoxidation of deposited coke) was employed after every recycle. The second, third and fourth tests have practically no difference. Thus, the reuse experiments also show one lost of activity of approximately $20 \%$, at the beginning of the test, comparing the first and fourth recycle. This is not due to coke deposition during the reaction, because thermal analysis (not showed) of the samples before and after reaction have the same weight lost. Maybe this lost of activity is due to the regeneration treatment. Comparing the conversion in the last minutes of reaction, all tests have practically the same conversion at the end, confirming the stability of this solid to the recycle.

\section{Conclusions}

The direct synthesis method for Al/SBA-15 was inefficient in incorporating aluminum into SBA-15 due to the low $\mathrm{pH}$ condition during its synthesis, which led to the leaching of aluminum. Therefore, it was not incorporated into the material.

Through the $\mathrm{pH}$ adjustment method, it was possible to synthesize Al/SBA-15 with a large amount of aluminum, but it led to a significant decrease in the specific area of the materials. It has been observed that the addition of $\mathrm{NaF}$ can accelerate the synthesis process. However, when $\mathrm{NaF}$ is added in high quantities with a high $\mathrm{pH}$, it can lead to the structural disorder of the material and the blocking of pores.

The $\mathrm{pH}$ factor was essential for the incorporation of aluminum. Materials with a $\mathrm{Si} / \mathrm{Al}$ ratio of 5 , required a $\mathrm{pH}$ 
of 4 to incorporate aluminum in the material; however, by increasing the $\mathrm{Si} / \mathrm{Al}$ ratio to $15, \mathrm{a} \mathrm{pH}$ increase to 8 was required for incorporation.

The aluminum NMR results indicate that it was possible to incorporate the aluminum atoms in the SBA-15 structure. However, this incorporation was not fully effective because many aluminum species are hexacoordinated or pentacoordinated. Because the amount of aluminum in the final product takes the $\mathrm{Si} / \mathrm{Al}$ ratios of the materials to values greater than 20 , much of the aluminum present is not part of the material structure but is instead present in the inner part of the channels, which can be deduced from the decrease of the microporous area and the presence of hexacoordinated aluminum.

The present study revealed that the catalytic reaction occurred via dehydration of ethanol, as the main products were ethylene and diethyl ether. The recycle study show that the materials have good catalytic stability. The activity and the catalytic stability confirms the presence of acid sites in the synthesized materials.

\section{Acknowledgments}

To PRHPB-222 for financial assistance. To ITQ/UPV Valencia/Spain for NMR analysis.

\section{References}

1. Corma A. From Microporous to Mesoporous Molecular Sieve Materials and Their Use in Catalysis. Chemical Reviews. 1997;97(6):2373-2420.

2. Kresge CT, Leonowicz ME, Roth WJ, Vartuli JC, Beck JS. Ordered mesoporous molecular sieves synthesized by a liquidcrystal template mechanism. Nature. 1992;359:710-712. DOI: $10.1038 / 359710 \mathrm{a} 0$

3. Vartuli JC, Kresge CT, Roth WJ, McCullen SB, Beck JS, Schmitt KD, et al. Designed Synthesis of Mesoporous Molecular Sieve Systems Using Surfactant-Directing Agents. In: Moser WR, ed. Advanced Catalysis and Nanostructered Materials. San Diego: Academic Press; 1996. p. 1-19.

4. Meynen V, Cool P, Vansant EF. Verified syntheses of mesoporous materials. Microporous and Mesoporous Materials. 2009;125(3):170-223. DOI: 10.1016/j.micromeso.2009.03.046

5. Zhao D, Feng J, Huo Q, Melosh N, Fredrickson GH, Chmelka BF, et al. Triblock Copolymer Syntheses of Mesoporous Silica with Periodic 50 to 300 Angstrom Pores. Science. 1998;279(5350):548-552. DOI: 10.1126/science.279.5350.548

6. Wu S, Han Y, Zou YC, Song JW, Zhao L, Di Y, et al. Synthesis of Heteroatom Substituted SBA-15 by the "pH-Adjusting" Method. Chemical Materials. 2004;16:486-492. DOI: 10.1021/ $\mathrm{cm} 0343857$
7. Gallo JMR, Bisio C, Gatti G, Marchese L, Pastore HO. Physicochemical Characterization and Surface Acid Properties of Mesoporous [Al]-SBA-15 Obtained by Direct Synthesis. Langmuir. 2010;26(8):5791-5800. DOI: 10.1021/la903661q

8. Selvam P, Krishna NV, Viswanathan B. Architecting mesoporous AlSBA-15: An overview on the synthetic strategy. Journal of the Indian Institute of Science. 2010;90(2):271-285.

9. Ma J, Qiang LS, Wang JF, Tang XB, Tang DY. Effect of different synthesis methods on the structural and catalytic performance of SBA-15 modified by aluminum. Journal of Porous Materials. 2011;18(5):607-614. DOI: 10.1007/s10934-010-9416-y

10. Jiang T, Tao H, Ren J, Liu X, Wang Y, Lu G. Fluoride ions assistant synthesis of extremely hydrothermal stable Al-SBA-15 with controllable Al content. Microporous and Mesoporous Materials. 2011;142(1):341-346. DOI: 10.1016/j.micromeso.2010.12.020

11. Li Y, Zhang W, Zhang L, Yang Q, Wei Z, Feng Z, et al. Direct Synthesis of Al-SBA-15 Mesoporous Materials via HydrolysisControlled Approach. The Journal of Physical Chemistry B. 2004;108(28):9739-9744. DOI: 10.1021/jp049824j

12. Ungureanu A, Dragoi B, Hulea V, Cacciaguerra T, Meloni D, Solinas V, et al. Effect of aluminium incorporation by the " $\mathrm{pH}$ adjusting" method on the structural, acidic and catalytic properties of mesoporous SBA-15. Microporous and Mesoporous Materials. 2012;163:51-64. DOI: 10.1016/j.micromeso.2012.05.007

13. Kruk M, Jaroniec M, Sayari A. Application of Large Pore MCM-41 Molecular Sieves To Improve Pore Size Analysis Using Nitrogen Adsorption Measurements. Langmuir. 1997;13(23):6267-6273. DOI: $10.1021 / 1 \mathrm{a} 970776 \mathrm{~m}$

14. Thommes M, Kaneko K, Neimark AV, Olivier JP, RodriguezReinoso F, Rouquerol J, et al. Physisorption of gases, with special reference to the evaluation of surface area and pore size distribution (IUPAC Technical Report). Pure and Applied Chemistry. 2015;87(910):1051-1069. DOI: $10.1515 /$ pac-2014-1117

15. Leofanti G, Padovan M, Tozzola G, Venturelli B. Surface area and pore texture of catalysts. Catalysis Today. 1998;41(13):207-219. DOI: 10.1016/S0920-5861(98)00050-9

16. Bhange P, Bhange DS, Pradhan S, Ramaswamy V. Direct synthesis of well-ordered mesoporous Al-SBA-15 and its correlation with the catalytic activity. Applied Catalysis A: General. 2011;400(12):176-184. DOI: $10.1016 /$ j.apcata.2011.04.031

17. Santos RCR, Pinheiro AN, Leite ER, Freire VN, Longhinotti E, Valentini A. Simple synthesis of A12O3 sphere composite from hybrid process with improved thermal stability for catalytic applications. Materials Chemistry and Physics. 2015;160:119130. DOI: 10.1016/j.matchemphys.2015.04.014

18. Stuckv GD, Zhao D, Yang P, Lukens W, Melosh N, Chmelka $\mathrm{BF}$. Using the organic-inorganic interface to define pore and macroscale structure. In: Bonneviot L, Béland F, Danumah C, Giasson S, Kaliaguine S, eds. Mesoporous Molecular Sieves 1998. Studies in Surface Science and Catalysis. Volume 117. Amsterdam: Elsevier Science; 1998. p. 1-12. 
19. Chen G, Wang L, Lei J, Zhang J. F- assistant synthesis of ultra-hydrothermally stable mesoporous silica by using nonionic organosilicon surfactant as templates. Microporous and Mesoporous Materials. 2009;124(1-3):204-209. DOI: 10.1016/j.micromeso.2009.05.011

20. Zukal A, Siklová H, C̄ejka J. Grafting of Alumina on SBA-15: Effect of Surface Roughness. Langmuir. 2008;24(17):98379842. DOI: $10.1021 / \mathrm{la} 801547 \mathrm{u}$

21. Galarneau A, Cambon H, Di Renzo F, Ryoo R, Choi M, Fajula F. Microporosity and connections between pores in SBA-15 mesostructured silicas as a function of the temperature of synthesis. New Journal of Chemistry. 2003;27(1):73-79. DOI: $10.1039 / \mathrm{b} 207378 \mathrm{C}$

22. Villarroel Rocha J, Barrera D, Sapag K. Improvement in the Pore Size Distribution for Ordered Mesoporous Materials with Cylindrical and Spherical Pores Using the Kelvin Equation. Topics in Catalysis. 2011;54(1-4):121-134. DOI: 10.1007/ s11244-011-9631-z

23. Fulvio PF, Pikus S, Jaroniec M. Short-time synthesis of SBA-15 using various silica sources. Journal of Colloid and Interface Science. 2005;287(2):717-720. DOI: 10.1016/j.jcis.2005.02.045

24. Choi DG, Yang SM. Effect of two-step sol-gel reaction on the mesoporous silica structure. Journal of Colloid and Interface Science. 2003;261(1):127-132. DOI: 10.1016/S00219797(03)00020-1
25. Muthu Kumaran G, Garg S, Soni K, Kumar M, Gupta JK, Sharma LD, et al. Synthesis and characterization of acidic properties of Al-SBA-15 materials with varying $\mathrm{Si} / \mathrm{Al}$ ratios. Microporous and Mesoporous Materials. 2008;114(1-3):103-109. DOI: 10.1016/j. micromeso.2007.12.021

26. Zheng Q, Grossardt J, Almkhelfe H, Xu J, Grady BP, Douglas JT, et al. Study of mesoporous catalysts for conversion of 2,3-butanediol to butenes. Journal of Catalysis. 2017;354:182-196. DOI: 10.1016/j. jcat.2017.08.017

27. Riseman SM, Massoth FE, Dhar QM, Eyrlng EM. Fourier transform infrared photoacoustic spectroscopy of pyridine adsorbed on silica-alumina and y-alumina. The Journal of Physical Chemistry. 1982;86(10):1760-1763. DOI: 10.1021/j100207a005

28. Yun JS, Bazardorj SE, Ihm SK. Acidity Control of Al-SBA-15 and Its Effect on the Catalytic Performance for Steam Reforming of Dimethyl Ether. Journal of Chemical Engineering of Japan. 2009;42(Suppl):s180-s184.

29. Saito Y, Niiyama H. Reaction mechanism of ethanol dehydration on/in heteropoly compounds: Analysis of transient behavior based on pseudo-liquid catalysis model. Journal of Catalysis. 1987;106(2):329-336

30. Varisli D, Dogu T, Dogu G. Ethylene and diethyl-ether production by dehydration reaction of ethanol over different heteropolyacid catalysts. Chemical Engineering Science. 2007;62(18-20):53495352 . 